\title{
La restauración de los sahumadores de la ofrenda 130 del Templo Mayor: \\ una puerta al conocimiento de la técnica de manufactura
}

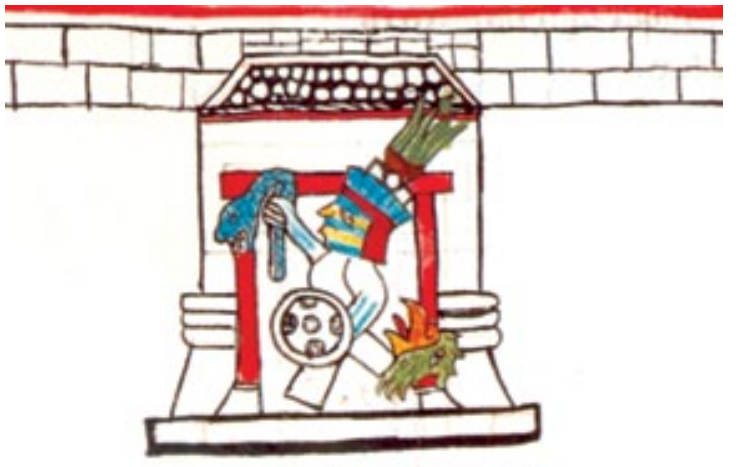

\author{
Seminario-Taller de Restauración de Cerámica \\ (STRC) ENCRYM-INAH
}

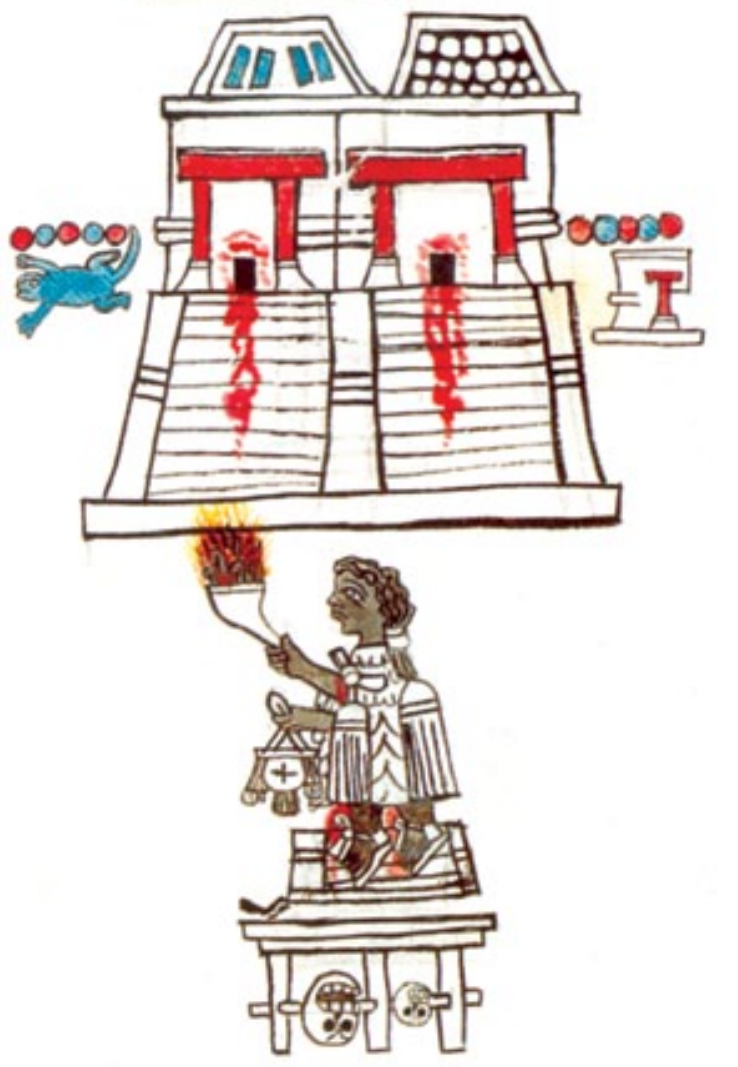

os sahumadores son elementos que están presentes en muchas culturas del mundo. En el México prehispánico se utilizaban en ceremonias y rituales, siempre en estrecha relación con resinas aromáticas como el copal, que se quemaba en su interior para purificar espacios, imágenes, objetos y personas, y así entablar una comunicación con las divinidades. En el caso de la cultura mexica, su uso quedó plasmado en diferentes manifestaciones culturales, como esculturas y códices, en donde los sahumadores aparecen representados acompañando imágenes de dioses y sacerdotes que los utilizan durante rituales (Figura 1).

Gracias a las excavaciones realizadas por el Proyecto Templo Mayor, Temporada 7 (PTM-7), coordinado por el doctor Leonardo López Luján, se descubrieron 31 sahumadores, correspondientes a la ofrenda 130, en contextos indirectamente asociados con el monolito de la diosa Tlaltecuhtli, frente a las escalinatas de la plataforma de la estructura del Templo Mayor, siguiendo el eje (oriente-poniente) que divide los adoratorios de Tláloc y Huitzilopochtli. Por el orden y la disposición en que se encontraron, es posible que los sahumadores se hubiesen colocado inmediatamente después de la realización de un ritual, que bien pudo haber sido la consagración de la ampliación del basamento piramidal, identificado como etapa IVa, del principal recinto religioso de los aztecas.

Los sahumadores pueden tener formas diversas: los aquí referidos se componen de una cazoleta hemisférica y un mango hueco, ornamentado en muchos casos con un remate de moño y una cabeza de serpiente. La decoración de la cazoleta consta de calados en forma de cruz de Malta y aplicaciones que simulan una cuerda (Figura 
FIGURA 2. Vista general del Sahumador A-03 después de la intervención de restauración (Fotografía: Elisa Carmona, 2010; cortesía: STRC, ENCRYM-INAH).
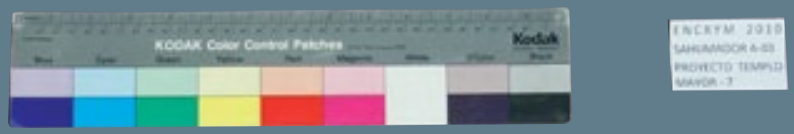

2); asimismo, presentan evidencias de policromía post-cocción. Independientemente de su utilización para la combustión de resinas, este tipo de sahumadores producían un sonido rítmico, logrado por el juego de pequeñas canicas de barro contenidas en el interior del mango hueco.

El hallazgo de esta colección de sahumadores coincidió con la planeación del curso 2010 del Seminario-Taller de Restauración de Cerámica (STRC) de la Escuela Nacional de Conservación, Restauración y Museografía del Instituto Nacional de Antropología e Historia (ENCRyMINAH), por lo que oportunamente recibimos la invitación del doctor López Luján y de la maestra Alejandra Alonso Olvera, de la Coordinación Nacional de Conservación del Patrimonio Cultural del instituto (CNCPC-INAH), para participar en su conservación. Las características de la colección eran ideales para contribuir a la formación de los alumnos, quienes tenían entonces la oportunidad de integrarse a un proyecto de investigación arqueológica interdisciplinaria, en una experiencia de trabajo única (Figuras 3 y 4).

En este tenor, las profesoras del STRC cooperamos con la arqueóloga Amaranta Argüelles y la restauradora Ana Bertha Miramontes, colaboradoras del PTM-7, durante el

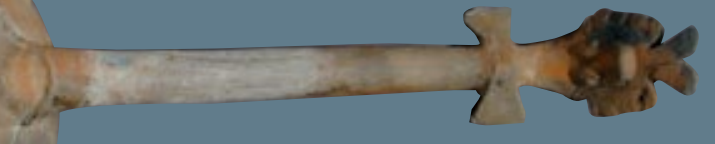

proceso de levantamiento de las piezas, lo que nos permitió conocer las condiciones específicas en las que se encontraban los objetos en el depósito (suelo arcilloso, alto nivel freático, piezas fracturadas pero, en su mayoría, completas), datos esenciales para planear y coordinar su restauración.

En la intervención de los sahumadores se obtuvieron datos importantes en torno a la técnica de manufactura, la dinámica de alteración y los procesos de intervención de las piezas, información que quedó registrada en el informe final (STRC, ENCRYM-INAH 2010) y que muestra el aprendizaje de los alumnos al culminar el segundo semestre de la Licenciatura en Restauración.

La posibilidad de observar detalladamente las huellas de manufactura fue una de las más valiosas aportaciones alcanzadas: al trabajar 25 de los 31 objetos con características similares fue posible identificar las técnicas mediante las que se elaboró cada uno de los elementos del sahumador (cazoleta, mango y remate), los patrones y las formas de unión, las marcas de fibras utilizadas como desgrasantes y los cortes o huellas dactilares dejadas al presionar la pasta sobre un molde preexistente.

Estas observaciones nos motivaron a intentar reproducir las piezas, con ayuda de los profesores de la asigna-

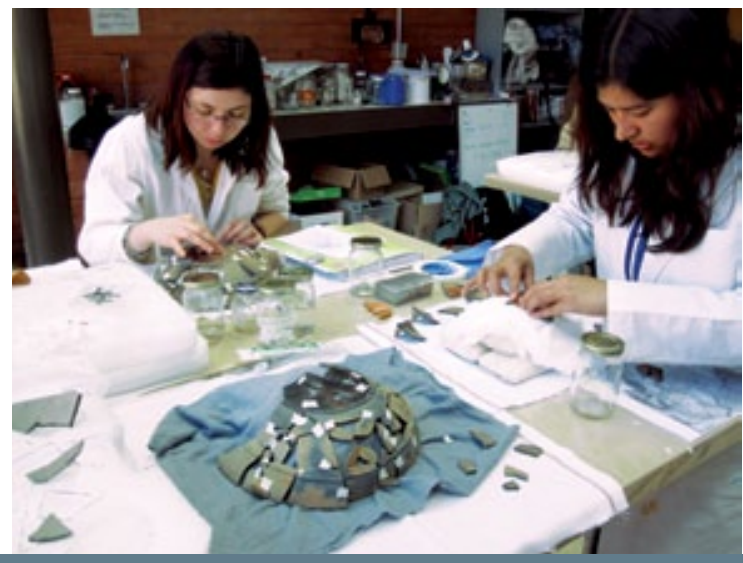

FIGURA 4. Restauración de la colección de sahumadores, proceso de unión de fragmentos (Fotografía: Laura Suárez Pareyón, 2010; cortesía: STRC, ENCRyM-INAH).
FIGURA 3. Seminario-Taller de Restauración de Cerámica, procesos de restauración de sahumadores (Fotografía: Laura Suárez Pareyón, 2010; cortesía: STRC, ENCRYM-INAH).

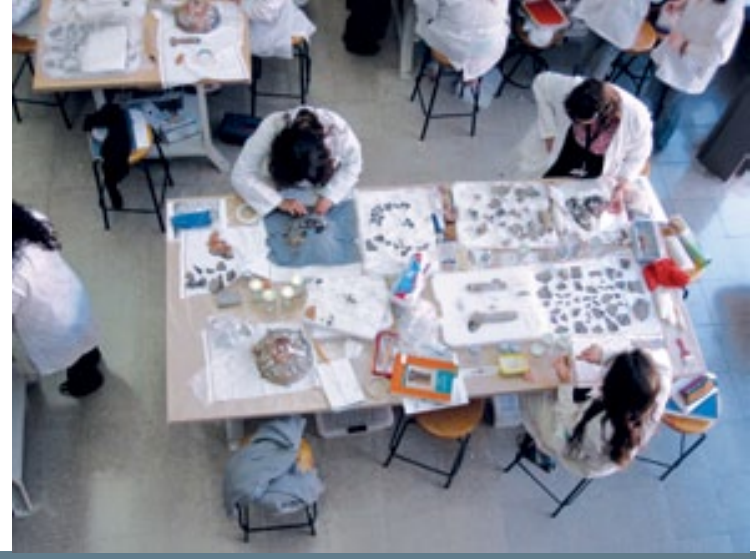


FIGURA 5. Reproducción de un sahumador

(Fotografía: Laura Suárez Pareyón, 2011;

cortesía: STRC, ENCRYM-INAH).

$\nabla$
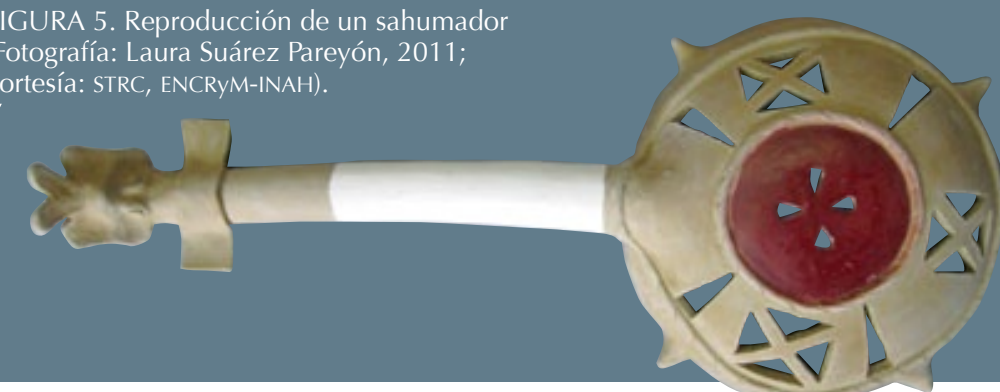

FIGURA 7. Reproducción de técnica de • manufactura: aplicación de decoraciones a un sahumador (Fotografía: Quetzalli

Paleo, 2011; cortesía: STRC, ENCRyM-INAH).

tura de Técnicas de Cerámica y Moldes de la ENCRyM, experimentación con la que, a su vez, comprobamos la información ya recabada visualmente y profundizamos en aspectos de la técnica empleada en su manufactura (Figura 5).

Como resultado de este ejercicio, se hizo evidente que la producción de los sahumadores fue llevada a cabo en serie por talleres especializados, que seguían patrones estandarizados. No hay que olvidar el caso de los 450 encontrados frente al templo de Ehécatl en Tlatelolco, que datan de esa misma época y comparten gran semejanza en cuanto a forma, diseño y técnica de manufactura, lo que hace pensar que su elaboración se realizaba a gran escala.

En lo referente a lo comprobado por nuestra experimentación, podemos decir que los sahumadores del Templo Mayor se manufacturaron en tres partes: el mango con una placa colocada sobre un soporte cilíndrico

FIGURA 6. Etapas de manufactura de un sahumador (Fotografía: Quetzalli Paleo,

2011; cortesía: STRC, ENCRYM-INAH).

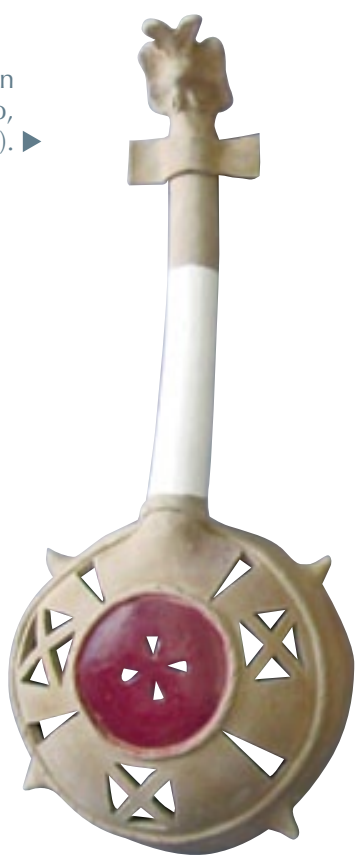

de madera; la cazoleta, a partir de una placa a la que se le daba forma con un molde; y los remates en forma de serpiente, facturados con moldes previamente realizados en arcilla (Figura 6).

Todos los elementos se unían agregando pasta y ensanchando el extremo de unión; en ese momento se hacía en la cazoleta una perforación que permitiría la salida de vapor acumulado en el mango durante la cocción, con lo que se evitaba su colapso por tratarse de un elemento hueco y cerrado. Ya unidos todos los elementos, se aplicaba la decoración y se realizaban los cortes en forma de cruz de Malta característicos de estas piezas (Figuras 7 y 8$)$.

Cuando la arcilla se encontraba más seca, se aplicaba el engobe rojo de la base, el cual se bruñía cuidadosamente (Figura 9) para dar paso a la cocción de las piezas. Finalmente la decoración podía complementarse con policromía post-cocción.

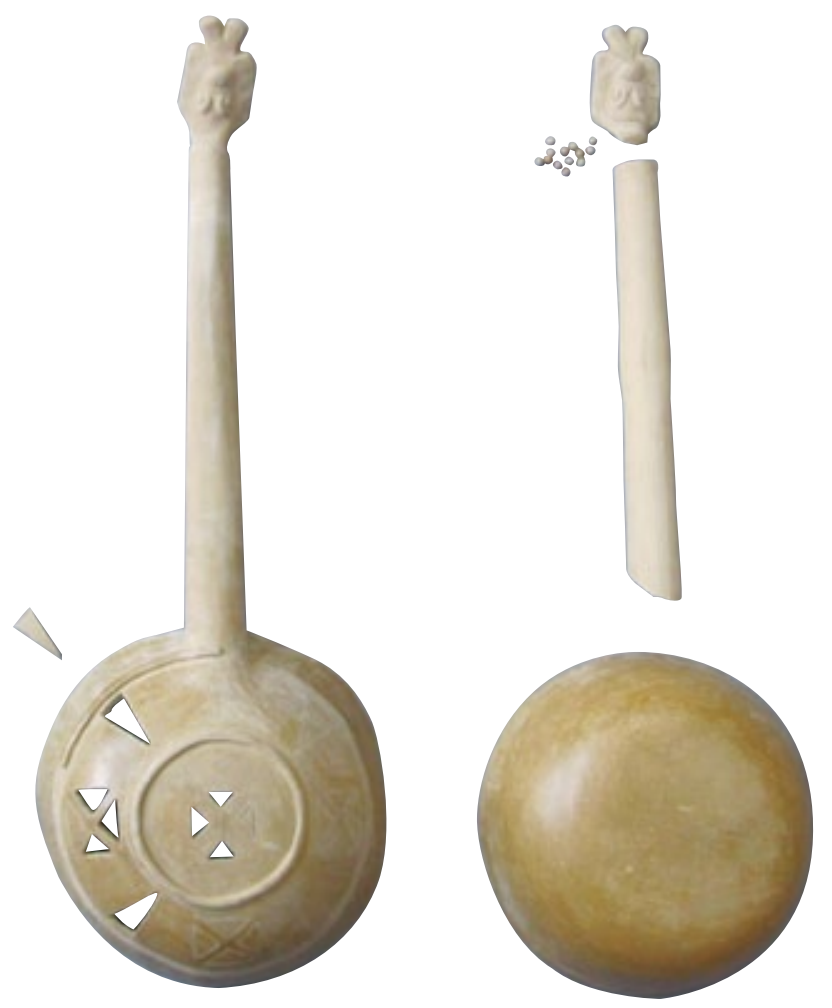




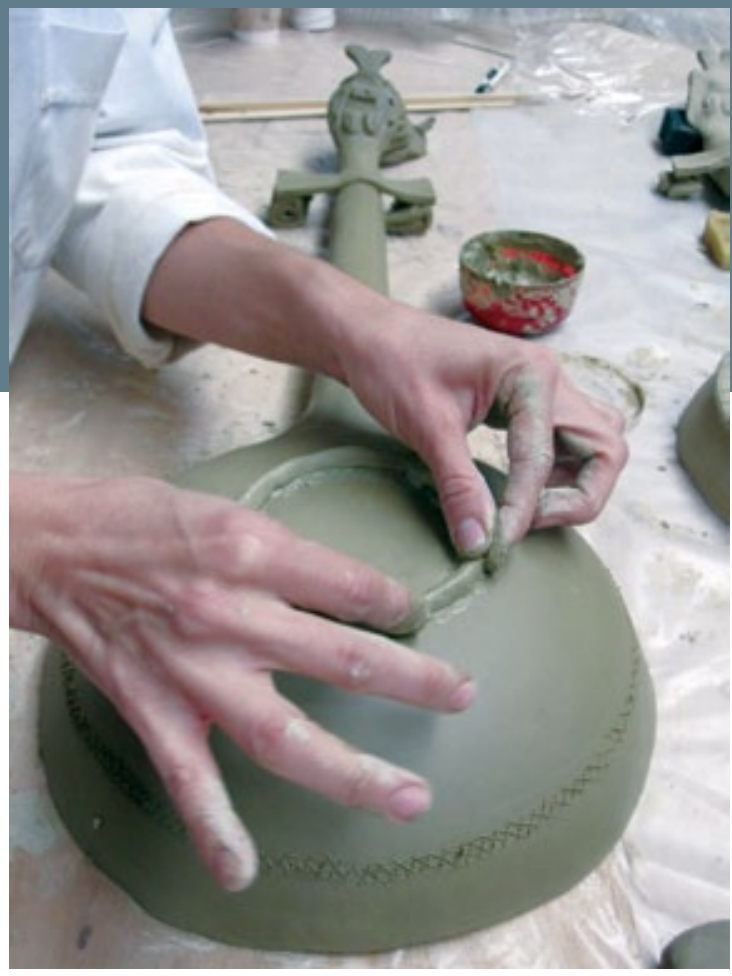

FIGURA 8. Reproducción de técnica de manufactura: decoración calada en forma

de cruz de Malta aplicada a un sahumador (Fotografía: Quetzalli Paleo, 2011; cortesía: STRC, ENCRYM-INAH).

FIGURA 9. Reproducción de técnica de manufactura: bruñido de engobe de hematita. (Fotografía de Laura Suárez Pareyón, 2011; cortesía: STRC, ENCRYM-INAH).
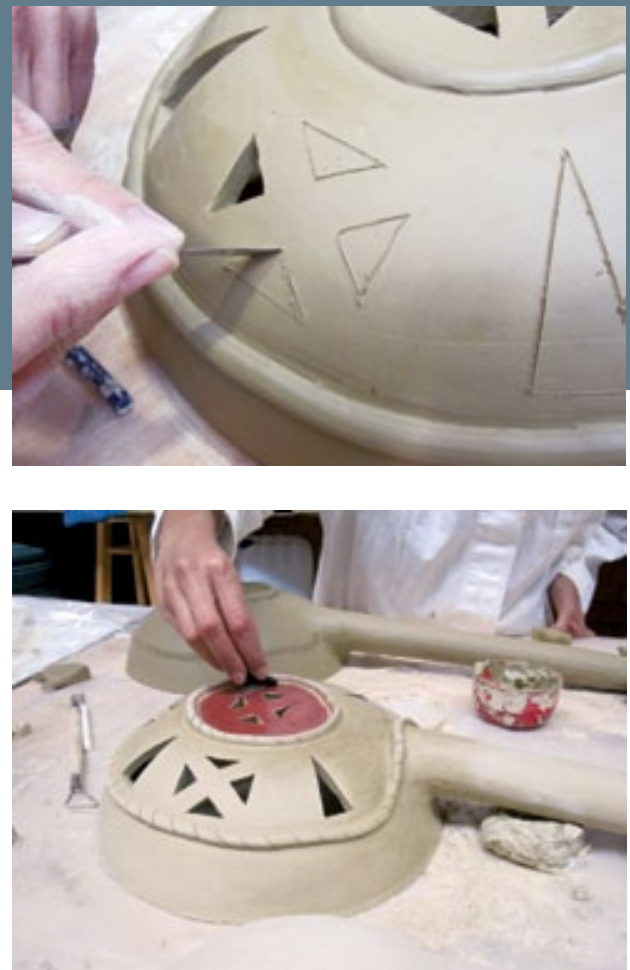

Gracias a este análisis sobre la técnica de manufactura, confirmamos que los artesanos mexicas conocían y manejaban a la perfección los materiales constitutivos de los sahumadores; por ejemplo, controlaban cuidadosamente al proceso de secado de la arcilla. Asimismo, con la ayuda tanto de especialistas del PTM-7 como de los colaboradores del STRC (ENCRYM-INAH), se logró obtener información adicional relacionada con las piezas, entre las que destaca la identificación de restos de resinas en el interior de las cazoletas y otras huellas de uso, elementos que ayudaron a definir los procesos de la restauración que habría de realizarse.

Podemos concluir que fue muy valioso el acercamiento de los alumnos al estudio de los materiales constitutivos, las técnicas empleadas en la factura y las problemáticas de conservación de la colección de sahumadores. Nuestra participación no sólo ayudó a la estabilización material de la colección, sino también a comprender la relevancia tanto de la ofrenda 130 como de su contexto, lo cual indica que el restaurador es un especialista que se aproxima a los bienes culturales de manera integral. Por ello, la ejecución de este proyecto confirma la necesidad de abrir paso a trabajos interdisciplinarios y al intercambio de información entre especialistas, tarea que se prioriza en todos los Seminarios-Talleres de la ENCRYM-INAH.

Finalmente, como resultado del trabajo conjunto del PTM-7 y del STRC, se inauguró el 29 de marzo, en el ves- tíbulo del Museo del Templo Mayor (MTM-INAH), la exposición temporal "Humo aromático para los dioses: una ofrenda de sahumadores al pie del Templo Mayor de Tenochtitlan" (López Lujan 2011), la cual se presentó al público hasta el 12 de agosto de 2012. En ésta se abordó de manera integral el trabajo interdisciplinario en torno a estos sahumadores y se mostraron los resultados obtenidos por cada una de las áreas de estudio, haciendo hincapié en su conservación-restauración.

\section{Referencias}

STRC, ENCRYM-INAH

2010 Informe de la restauración de la colección de sahumadores de la ofrenda 130, Proyecto Templo Mayor temporada 7, manuscrito, México, STCR-ENCRYM-INAH.

Sahagún, Bernardino de

1993 Primeros memoriales, edición facsimilar, Norman, University of Oklahoma Press.

López Luján, Leonardo (coord.)

2011 Catálogo de la exposición: Humo aromático para los dioses: una ofrenda de sahumadores al pie del Templo Mayor de Tenochtitlan, México, Conaculta-MTM/INAH.

Título en inglés: The Restoration of Incense Burners from Offering 130 in the Templo Mayor: a Door to Understanding the Manufacturing Technique 